DEMOGRAPHIC RESEARCH

VOLUME 29, ARTICLE 18, PAGES 473-506

PUBLISHED 11 SEPTEMBER 2013

http://www.demographic-research.org/Volumes/Vol29/18/

DOI: $10.4054 /$ DemRes.2013.29.18

Research Article

Explaining the rural-urban gap in infant mortality in India

Nandita Saikia

Abhishek Singh

Domantas Jasilionis

Faujdar Ram

๑ 2013 Nandita Saikia, Abhishek Singh, Domantas Jasilionis \& Faujdar Ram.

This open-access work is published under the terms of the Creative Commons

Attribution NonCommercial License 2.0 Germany, which permits use,

reproduction \& distribution in any medium for non-commercial purposes, provided the original author( $(s)$ and source are given credit.

See http:// creativecommons.org/licenses/by-nc/2.0/de/ 


\section{Table of Contents}

$1 \quad$ Introduction $\quad 474$

$2 \quad$ Data and methods

2.1 Data 477

2.2 Methods 480

3 Results 481

3.1 Trends in the rural-urban gap in infant mortality in India 481

3.2 Socioeconomic determinants of rural-urban gap in infant mortality 482

$4 \quad$ Discussion and conclusions $\quad 488$

References 493

Appendix: Steps of Fairlie Decomposition (2005) 502 


\title{
Explaining the rural-urban gap in infant mortality in India
}

\author{
Nandita Saikia ${ }^{1}$ \\ Abhishek Singh ${ }^{2}$ \\ Domantas Jasilionis $^{3}$ \\ Faujdar Ram ${ }^{4}$
}

\begin{abstract}
BACKGROUND

Prior studies suggest that infant mortality in rural areas of India is substantially higher than in urban areas. However, little is known about the determinants explaining such excess of rural mortality.
\end{abstract}

\section{OBJECTIVE}

This study systematically assesses the role of socioeconomic and maternal and child health $(\mathrm{MCH})$ care-related programme factors in explaining the rural-urban gap in infant mortality during the past two decades.

\section{METHODS}

Long-term changes in rural and urban infant mortality were assessed using Sample Registration System (SRS) data. Binary logistic regression was used to analyse the association between socioeconomic and $\mathrm{MCH}$ care-related programme factors and infant mortality using data from the three rounds of the National Family Health Survey (NFHS). Fairlie's decomposition technique was applied to understand the relative contribution of different co-variates to the rural-urban gap in infant mortality.

\section{RESULTS}

Relative inequality between rural and urban India has increased over time. The ruralurban gap in infant mortality can be largely explained by the distributions of the covariates in rural and urban area. The largest part of the rural disadvantage in infant mortality is attributable to the underlying disadvantage in household wealth and maternal education, whereas breastfeeding and knowledge of Oral Rehydration Solution

\footnotetext{
${ }^{1}$ Institute of Economic Growth, University Enclave, Delhi, India. E-mail: nanditasts@ gmail.com.

${ }^{2}$ International Institute for Population Sciences, Mumbai, India.

${ }^{3}$ Max Planck Institute for Demographic Research, Germany.

${ }^{4}$ International Institute for Population Sciences, Mumbai, India.
} 
has contributed to narrowing the gap. The share of women using modern contraceptive methods and the percentage of fully vaccinated children in the community have also contributed to widening the rural-urban gap in infant mortality.

\section{CONCLUSION}

In addition to strengthening $\mathrm{MCH}$ programmes in rural areas, substantial efforts must also be made to improve household wealth and female education levels.

\section{Introduction}

Gaps in child mortality between rich and poor countries are wide and growing, and there is evidence of growing inequity within countries (Victora et al. 2003; Mulholland et al. 2008). While substantial progress has been made in reducing child deaths, children from poor/disadvantaged households remain disproportionately vulnerable across all regions of the developing world (UNICEF 2010). Although infant mortality in India has declined dramatically over the past four decades, tremendous variations still persist across population sub-groups and geographical areas. The 2009 infant mortality rates (IMR) ranged from a low of 10 in urban Goa to a high of 72 in rural Madhya Pradesh (Registrar General of India 2011b). Several past studies have investigated socioeconomic factors affecting infant mortality in India (Jain 1985; Arnold et al. 1998; Kravdal 2004; Mohanty 2011; Singh et al. 2011; Po and Subramanian 2011), yet hardly any study has examined long-term trends in the ruralurban gap in infant mortality. Rural infants in India face higher mortality risks than their urban counterparts, irrespective of the average mortality level, than in most other developing countries (Table 1).

The rural-urban mortality differential in the context of many developed and developing countries has been well documented. The literature, primarily from the developed world, suggests a dynamic association between rural-urban residence and mortality risks during infancy; whereby the relationship between the two changes depending on country of residence and over historical time periods. For instance, there was a strong rural-urban mortality differential in $19^{\text {th }}$ century Western Europe and the risk of premature death was higher in cities/towns, where living conditions were poor and health and medical facilities rudimentary (Van Poppel 1989; Woods 2003; Cain and Hong 2009). However, by the end of the $19^{\text {th }}$ century, the urban disadvantage in mortality risks disappeared after a number of public health interventions had been implemented and the urban environment improved (Van Poppel 1989; Haines 1995). 
Table 1: Infant mortality rate (1000 live births) in India and states by type of residence, 2009

\begin{tabular}{lcccc|lcccr}
\hline Country/States & Total & Rural & Urban & Gap & Country/States & Total & Rural & Urban & Gap \\
\hline India & 50 & 55 & 34 & 21 & Madhya Pradesh & 67 & 72 & 45 & 27 \\
Andhra Pradesh & 49 & 54 & 35 & 19 & Maharashtra & 31 & 37 & 22 & 15 \\
Arunachal Pradesh & 32 & 35 & 14 & 21 & Manipur & 16 & 18 & 11 & 7 \\
Assam & 61 & 64 & 37 & 27 & Meghalaya & 59 & 61 & 40 & 21 \\
Bihar & 52 & 53 & 40 & 13 & Mizoram & 36 & 45 & 19 & 26 \\
Chhattisgarh & 54 & 55 & 47 & 8 & Nagaland & 26 & 27 & 23 & 4 \\
Delhi & 33 & 40 & 31 & 9 & Orissa & 65 & 68 & 46 & 22 \\
Goa & 11 & 11 & 10 & 1 & Punjab & 38 & 42 & 31 & 11 \\
Gujarat & 48 & 55 & 33 & 22 & Rajasthan & 59 & 65 & 35 & 30 \\
Haryana & 51 & 54 & 41 & 13 & Sikkim & 34 & 36 & 21 & 15 \\
Himachal Pradesh & 45 & 46 & 28 & 18 & Tamil Nadu & 28 & 30 & 26 & 4 \\
Jammu \& Kashmir & 45 & 48 & 34 & 14 & Tripura & 31 & 33 & 20 & 13 \\
Jharkhand & 44 & 46 & 30 & 16 & Uttar Pradesh & 63 & 66 & 47 & 19 \\
Karnataka & 41 & 47 & 31 & 16 & Uttarakhand & 41 & 44 & 27 & 17 \\
Kerala & 12 & 12 & 11 & 1 & West Bengal & 33 & 34 & 27 & 7 \\
\hline
\end{tabular}

Source: Registrar General of India 2011b.

In the case of developing countries, however, the picture is different and more complex. Demographic and Health Surveys and other important data sources for many developing countries suggest that IMR are significantly higher in rural than in urban areas (Knöbel, Yang, and Ho 1994; Sastry 1997; Gould 1998; Heaton and Forste 2003; Cai and Chongsuvivatwong 2006; Poel, O'Donnell, and Doorslaer 2009; Bocquier, Madise, and Zulu 2011). Nearly all studies that have examined rural-urban differences in demographic and health outcomes in South Asian countries reveal rural children's disadvantages in terms of mortality during infancy and early childhood (Sathar 1985; Knöbel, Yang, and Ho 1994; Pandey et al. 1998; Wang et al. 2010; Pham et al. 2011). Many countries have also experienced a diminishing rural-urban gap in child mortality in the past few decades (Islam and Azad 2008).

Studies have attributed the rural disadvantage in infant mortality in less developed countries to the so-called 'urban bias' (Crenshaw and Ameen 1993), which indicates a disproportionate benefit gained by an urban population in the allocation of public resources (Lipton 1977; Redclift 1984). Studies have shown a significant relationship between this urban advantage in terms of health care facilities and urban-rural mortality gaps in developing countries, including India (Akbar 1985; Balarajan, Selvaraj, and Subramanian 2011). Usually, urban-based health care services in India continue to 
receive a larger share of public resources, resulting in lower investments in rural health facilities (Balarajan, Selvaraj, and Subramanian 2011).

Although several studies have examined the rural-urban differential in mortality risks during infancy, systematic attempts to understand the factors explaining the ruralurban gap in infant and child mortality are limited. Recent work by Poel, O'Donnell, and Doorslaer (2009) in six Francophone countries in Central and West sub-Saharan Africa demonstrated that household characteristics explained two-thirds of the total rural-urban gap in mortality risks during infancy. Another study conducted in Brazil attributed the urban advantage in infant and child survival to better socioeconomic and behavioural characteristics at both individual/household and community levels in urban areas (Sastry 1997). Poel, O'Donnell, and Doorslaer (2007) found a diminishing ruralurban mortality risk during early childhood when adjusting for household wealth in 19 countries. Moreover, this study found higher mortality rates in urban areas than in rural areas when the results were adjusted for household wealth in a few countries. Ruralurban gaps in nutritional status, income, and parental education - particularly mother's education - were found in a few studies to contribute to the rural-urban gap in child mortality (O'Donnell et al. 2008; Sastry 1997).

What are those factors which do not allow rural India to reduce its infant mortality to that of urban India? Examining this particular concern is extremely important taking into account that 1) the Indian population is still primarily rural and 2) the pace of urbanisation is relatively slow. According to the 2011 census of India, approximately $69 \%$ of the population lives in rural area (Registrar General of India 2011a). In the past eleven decades, the share of urban population has increased by only $13 \%$ (from $18 \%$ in 1901 to $31 \%$ in 2011) (Bhagat 2011). Because the share of rural population is so large, combating rural infant mortality would lead to a greater effect (steeper decline) on the reduction of infant mortality at the level of entire country.

Given the lack of evidence on the determinants of the rural-urban gap in child mortality in India, the present study aims to identify the major socioeconomic and $\mathrm{MCH}$ care-related programme factors explaining the rural-urban gap in infant mortality in India over the past two decades. This study has become even more important because the Government of India has implemented several new policy measures to improve the health of the rural population. 


\section{Data and methods}

\subsection{Data}

We used two different datasets to investigate long-term trends in rural-urban gaps in infant mortality and factors affecting these. The description of trends is based on data from the Sample Registration System (SRS) for the period 1971-2009 (Office of the Registrar General \& Census Commissioner (India) 2009; Registrar General of India 2009, 2011b). The SRS was introduced as a pilot scheme in some selected Indian states in 1964-65 in order to generate reliable estimates of fertility and mortality at the national and state levels. It was converted into a full-scale system in 1969-70. A detailed discussion of SRS can be found in Bhat 2002 or Saikia et al. 2011.

The examination of factors associated with the rural-urban gap in infant mortality in India is based on data from the National Family Health Survey (NFHS). The NFHS is a large-scale, cross-sectional, multi-round survey conducted in a nationally representative sample of households throughout India. Under the stewardship of the Ministry of Health and Family Welfare, Government of India, three rounds of the NFHS were conducted in 1992-93, 1998-99, and 2005-06 (IIPS 1995; IIPS and ORC Macro 2000; IIPS and ORC Macro 2007). The objective of the NFHS was to provide national and state level estimates of fertility, family planning, infant and child mortality, reproductive and child health, nutrition of women and children, the quality of health and welfare services, and socioeconomic conditions.

The NFHS 1992-93 (NFHS-1) comprises interviews with 88,562 households and 89,777 ever-married women of age 13-49 years in 24 states and the National Capital Territory of Delhi. The second round of NFHS (NFHS-2) covered 91,196 households and 89,199 ever-married women of age 15-49 across all the 26 states of India. In addition to interviewing ever-married women of age 15-49, NFHS-3 interviewed never-married women of the same age group and both ever-married and never-married men of age 15-54. In total, NFHS 3 interviewed 124,385 women of age 15-49 and 74,369 men of age $15-54$ from all 29 states. The three NFHS surveys used standardized questionnaires, sample designs, and field procedures to collect data. A detailed description of the survey design of the three NFHS is available in the respective national reports (IIPS 1995; IIPS and ORC Macro 2000, 2007). The household and eligible women response rates were consistently above 90 per cent in each of the three NFHS surveys.

An important survey instrument in all the three rounds of NFHS was the questionnaire on women, which collected detailed information on birth histories, health, nutrition, and related information on mothers and children. The birth history data allows 
for estimates of IMR and examination of factors associated with infant mortality in India and its states.

The NFHS adopted the definitions given by the Census of India for classifying rural and urban areas. The Census of India defines 'urban area' based on two criteria. First, the state government grants municipal status-corporation, municipal council, notified town area committee, or nagar panchayat - to a settlement. Such settlements are known as statutory or municipal towns in the Census definition of urban areas. Second, settlements that do not have municipal status but satisfy certain demographic and economic criteria (a population of more than 5000, a density of 400 persons per square kilometer, and 75 per cent male workforce in the non-agricultural sector) are also seen as urban areas (Office of the Registrar General \& Census Commissioner India 2013). Any settlement that does not fall in either of the two categories is considered to be a rural area.

\section{Outcome Variable}

We used the information on births in three years preceding the survey date in each of the three NFHS rounds in the analysis. Furthermore, we excluded the births during the 12 months preceding each survey date from the analysis, as these were censored cases. Thus our analysis is based on a sample of babies born 12-35 months prior to the three NFHS survey dates. Our outcome variable 'infant death' was assigned a value of 1 if the child died before age 12 months and 0 if the child was alive at least until age 12 months.

\section{Exposure Variables}

A number of studies have highlighted the role of socioeconomic, demographic and community variables in explaining infant mortality in various countries (Caldwell 1979; Caldwell and McDonald 1982; Trussell and Hammerslough 1983; Mosley and Chen 1984; Forste 1994; Sastry 1996; Das Gupta 1997; Rutstein 2000; Kuate-Defo and Diallo 2002; Kravdal 2004; Hosseinpoor et al. 2006; USAID 2009; Mounts et al. 2011). Accordingly, we controlled for a number of socioeconomic, demographic, and $\mathrm{MCH}$ care-related programme variables in our analysis. The socioeconomic variables included in the models were household wealth index, mother's education (no education; primary; secondary and higher), mother's working status (working; not working), mother's exposure to media (not exposed; exposed), religion (Hindu; Muslim; others), and caste (Scheduled Castes; Scheduled Tribes; others) of the household head.

The demographic variables included in the models were sex of the index child, birth interval (first born; second order birth and birth interval less than twenty four months; second order birth and birth interval equal to or more than twenty four months; third or higher order birth and birth interval less than twenty four months; third or 
higher order birth and birth interval equal to or more than twenty four months), mother's age at birth of the index child, size of the baby at birth and proportion of children who were of birth order 4 or more in the community. These variables have a significant association with infant mortality (Gubhaju 1985; Sastry 1996; Manda 1999; Kembo and Ginneken 2009; Poel, O'Donnell, and Doorslaer 2009; Sastry and Burgard 2011). The size of the baby at birth was included as a proxy for birth weight, as the birth weights were not available for a significant majority of newborns in the NFHS.

We also included a set of $\mathrm{MCH}$ care-related community-level variables in the analysis. The selection of community-level variables depended heavily on the demographic literature related to determinants of infant mortality (Jain 1985; Bongaarts 1987; Shimouchi, Ozasa, and Hayashi 1994; Victora et al. 1996; Victora et al. 2000; Tsui and Creanga 2009; Ghosh and James 2010; Soest and Saha 2012). We included the proportion of mothers aware of oral rehydration solution (ORS), proportion of currently married women using modern contraception methods, proportion of children who received the recommended set of childhood vaccinations, and the proportion of caesarean births in the community as community-level variables.

Other $\mathrm{MCH}$ care-related variables include breastfeeding and place of delivery (health facility; others) (Yoon et al. 1996; Betrán et al. 2001; Chen and Rogan 2004). Following the recommendations of previous studies (Forste 1994; Manda 1999), we used breastfeeding status as a time varying covariate (expressed in months) from birth to either death or the end of the observation. Another important determinant of mortality outcome in India is region of residence (Claeson et al. 2000; Subramanian et al. 2006; Saikia et al. 2011). Accordingly, we also included region of residence in our analysis. This variable was coded into six categories (north; central; east; northeast; west; south) based on the NFHS classification.

In our study, the household wealth index was computed using information on a number of household assets including possession of agricultural land and size of the land, consumer durables, and quality of housing. In the absence of direct and reliable information on household income and expenditure information in the NFHS, this type of proxy measure for household wealth status has been used successfully in many earlier studies (Vyas and Kumaranayake 2006; O’Donnell et al. 2008; Singh et al. 2011).

We could not include variables like 'source of drinking water', 'sanitation', 'cooking fuel' etc. in our analysis because of the possible collinearity with wealth index. These variables were used in the construction of the wealth index in NFHS surveys. 


\subsection{Methods}

Population-weighted dispersion measures of infant mortality (DMM) and Gini coefficients were applied to estimate the trend in absolute and relative rural-urban differentials in infant mortality from 1971-2011. The DMM is defined as the average absolute inter-population difference in the mortality indicator (here, it is IMR) across all pairs of populations, weighted by their sizes (Moser et al. 2005). The decreases and increases in DMM show the decrease and increase in absolute inequality among the rural and urban population expressed in infant deaths per thousand live births (for details, see Moser et al. 2005). Theoretically, DMM must always be greater than zero. The DMM equal to zero refer to a perfect equality in mortality by population subgroups under consideration. On the other hand, the Gini coefficient refers to the relative inter-regional inequality and is equal to the DMM divided by the average infant mortality rate in the population (Shkolnikov et al. 2003, 2012). The Gini coefficient may also vary between zero and one. When multiplied by 100 this coefficient shows the average relative difference as a percentage of the average infant mortality rate (Shkolnikov et al. 2012).

Using three rounds of NFHS data, we carried out a binary logistic regression model to examine the association between infant mortality and exposure variables. All the exposure variables were tested for possible multicollinearity before putting them into the binary logistic regression model.

One of the common approaches used in the past few decades to identify and quantify group differences in health, labour market, and other outcomes is the BlinderOaxaca decomposition (Blinder 1973; Oaxaca 1973). It aims to explain the distribution of the outcome variable in question by a set of factors that vary systematically with socioeconomic status (Oaxaca 1973; O'Donnell et al. 2008). In our study, this reveals how the difference in IMR between rural and urban areas can be explained by inequalities in socioeconomic status (O'Donnell et al. 2008). This technique, however, is not appropriate if the outcome variable is binary, such as infant death (Fairlie 2005). Hence, we used the extension of the Blinder-Oaxaca technique (Fairlie 2005) that is appropriate for binary models to decompose the rural-urban gap in infant mortality risk into contributions that can be attributed to different factors. We used the fairlie command available in 'STATA 10' and 1000 random subsamples of rural infants to calculate their means. Since the independent contribution of each variable (say, $X_{1} \&$ $X_{2}$ ) in the non-linear decomposition depends on the order in which the variables are introduced in the model, we randomised the order of the variables as suggested by Fairlie (2005) to get robust estimates. The decomposition method proposed by Fairlie (2005) is described in detail in Appendix 1. 


\section{Results}

\subsection{Trends in the rural-urban gap in infant mortality in India}

Table 1 shows a considerable rural disadvantage in infant survival at the national level and in certain states like Madhya Pradesh, Assam, and Orissa. Surprisingly, rural-urban gaps in IMR were also found in socioeconomically and demographically better performing states such as Goa and Kerala.

The trend in the rural-urban gap in infant mortality suggests that the gap has remained almost the same over the past four decades (Figure 1). The trends in DMM and Gini coefficient present an interesting picture of the rural-urban gap in infant mortality (Figure 2). While the DMM has decreased from 9.03 in 1971 to 4.53 in 2011, the Gini coefficient has increased from 7.00 in 1971 to 9.05 in 2011. Thus, although the absolute inequality in rural-urban IMR has decreased over time, the relative inequality with respect to total IMR in India has increased. Examination of the rural-urban infant mortality differential using three rounds of NFHS also gives us a similar picture of urban advantage over rural for recent years.

Figure 1: Trend of infant mortality in India by type of residence, 1971-2009

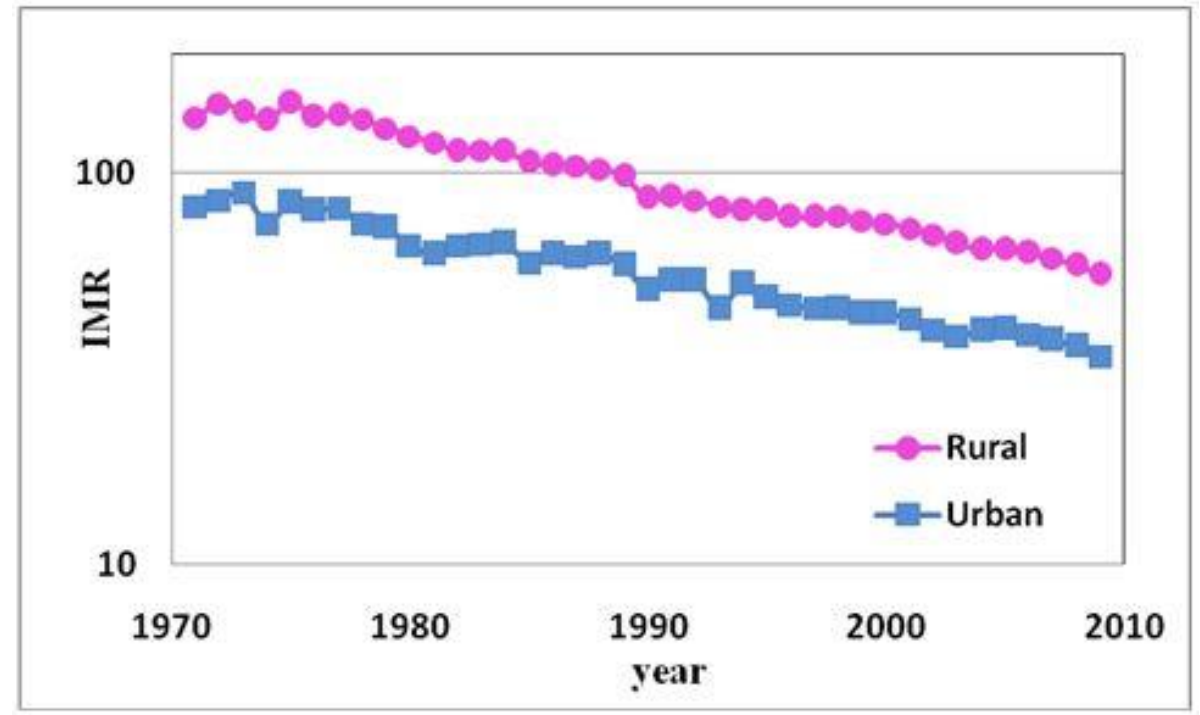

Source: Office of the Registrar General \& Census Commissioner India, 2009; Registrar General of India, 2009; Registrar General of India, 2011b.

Note: $\mathrm{Y}$-axis is in logarithmic scale. 
Figure 2: $\quad$ Trend in Gini coefficient (multiplied by 100) and Dispersion Measure in Mortality (DMM) for infant mortality in India, 1971-2011

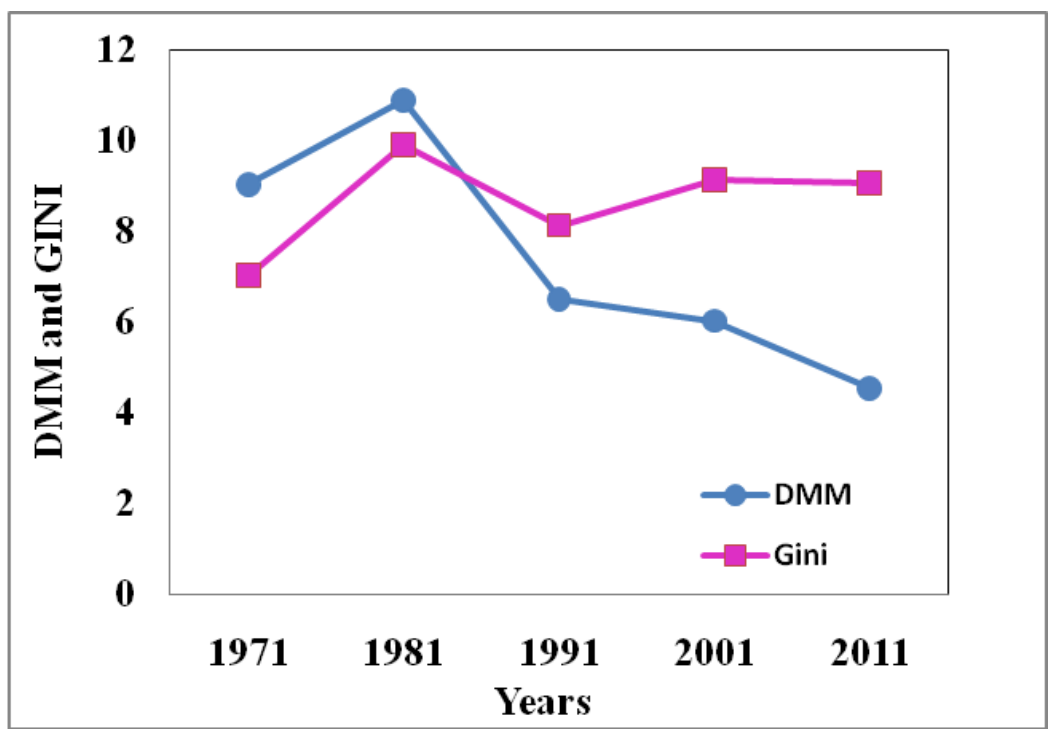

Note: We consider IMR for the year 2009 and population composition from 2011 Census to estimate DMM and Gini for 2011.

\subsection{Socioeconomic determinants of rural-urban gap in infant mortality}

Table A1 in the appendix shows the descriptive statistics of the covariates used in the decomposition of the rural-urban gap in infant mortality risk (NFHS 1992-93, 199899, and 2005-06).

We carried out a binary logistic regression analysis to examine the factors associated with infant mortality in India in the three NFHS surveys (pooled data for 1992-93, 1998-99, and 2005-06). Table 2 shows coefficients obtained from binary logistic regression and corresponding significance levels. Results adjusted for other socioeconomic, demographic, and community-level variables suggest a significant association between the sex of the baby and infant mortality - female babies had lower odds of dying during infancy compared to males. Breastfeeding was negatively associated with infant mortality. Birth interval was also significantly associated with infant mortality. Infants who were average or over average in size had a significantly lower risk of infant mortality compared to infants below average size at birth. A negative association was found between maternal age at birth of index child and infant 
mortality - babies born to women aged 21 years or more had significantly lower odds of infant mortality compared to babies born to women aged 20 years or less.

\section{Table 2: $\quad$ Adjusted associations between infant mortality and its determinants from pooled National Family Health Survey (1992-93, 1998-99, and 2005-06)}

\begin{tabular}{|c|c|c|}
\hline Covariates & Coefficients & $P>z$ \\
\hline \multicolumn{3}{|l|}{ Socioeconomic variable } \\
\hline Wealth index (continuous) & -0.017 & 0.000 \\
\hline \multicolumn{3}{|l|}{ Maternal education (Categorical) } \\
\hline \multicolumn{3}{|l|}{ No education ${ }^{\mathrm{R}}$} \\
\hline Primary education & -0.166 & 0.012 \\
\hline Secondary education & -0.45 & 0.000 \\
\hline Higher education & -0.846 & 0.000 \\
\hline \multicolumn{3}{|l|}{ Mother work status (Categorical) } \\
\hline \multicolumn{3}{|l|}{ Not working ${ }^{\mathrm{B}}$} \\
\hline Working & 0.135 & 0.009 \\
\hline \multicolumn{3}{|l|}{ Mothers' mass media exposure (Categorical) } \\
\hline \multicolumn{3}{|l|}{ Not exposed } \\
\hline Exposed & 0.065 & 0.242 \\
\hline \multicolumn{3}{|l|}{ Religion (Categorical) } \\
\hline \multicolumn{3}{|l|}{$\mathrm{Hindu}^{\mathrm{K}}$} \\
\hline Muslim & -0.217 & 0.001 \\
\hline Christian & -0.409 & 0.001 \\
\hline Others & -0.299 & 0.013 \\
\hline \multicolumn{3}{|l|}{ Caste (Categorical) } \\
\hline \multicolumn{3}{|l|}{ Others $^{\mathrm{R}}$} \\
\hline Scheduled Castes & 0.052 & 0.406 \\
\hline Scheduled Tribes & -0.107 & 0.181 \\
\hline \multicolumn{3}{|l|}{ Demographic Variables } \\
\hline \multicolumn{3}{|l|}{ Sex of the index child } \\
\hline \multicolumn{3}{|l|}{ Male $^{\mathrm{K}}$} \\
\hline Female & -0.122 & 0.006 \\
\hline \multicolumn{3}{|l|}{ Birth order \& birth interval (Categorical) } \\
\hline \multicolumn{3}{|l|}{ First born ${ }^{\mathrm{H}}$} \\
\hline Second order birth and birth interval less than 24 months & 0.184 & 0.031 \\
\hline Second order birth and birth interval more than equal to 24 months & -0.281 & 0.000 \\
\hline Third or more order birth and birth interval less than 24 months & 0.279 & 0.001 \\
\hline Third or more order birth and birth interval more than equal to 24 months & -0.192 & 0.019 \\
\hline \multicolumn{3}{|l|}{ Maternal age at birth (completed years) (categorical) } \\
\hline \multicolumn{3}{|l|}{11 to 20 year $^{\mathrm{K}}$} \\
\hline 21 to 30 years & -0.206 & 0.001 \\
\hline 31 and above & -0.578 & 0.027 \\
\hline \multicolumn{3}{|l|}{ Size of the baby (categorical) } \\
\hline \multicolumn{3}{|l|}{ Average or more than average $\mathrm{H}^{\mathrm{H}}$} \\
\hline Smaller than average & 0.641 & 0.000 \\
\hline Proportion of birth order with order 4 or more in community (Continuous) & -0.003 & 0.981 \\
\hline
\end{tabular}


Table 2: (Continued)

\begin{tabular}{lcc}
\hline Covariates & Coefficients & P>z \\
\hline $\begin{array}{l}\text { Maternal and Child Health care related Individual level variables } \\
\text { Breastfeeding (Continuous) }\end{array}$ & -0.325 & 0.000 \\
Place of delivery (categorical) & & \\
Home Delivery & & \\
Institutional Delivery & -0.259 & 0.000 \\
Maternal and Child Health Care related community level variables & & \\
proportion of women who have ORS knowledge (continuous) & 0.166 & 0.283 \\
proportion of C sections' birth (Continuous) & -0.161 & 0.142 \\
proportion of women using modern contraceptive (Continuous) & -0.827 & 0.000 \\
proportion fully vaccinated children (Continuous) & -0.586 & 0.000 \\
Others & & \\
Region (Categorical) & & \\
South ${ }^{\mathrm{H}}$ & & \\
North & & \\
Central & 0.237 & 0.006 \\
East & 0.519 & 0.000 \\
West & 0.531 & 0.000 \\
North-East & 0.123 & 0.218 \\
Time & 0.212 & 0.052 \\
National Family Health Survey $\mathbf{1}$ & & \\
National Family Health Survey 2 & & \\
National Family Health Survey 3 & 0.044 & 0.433 \\
\hline Number of observations & -0.154 & 0.012 \\
Pseudo R Square & 65695 \\
\hline
\end{tabular}

Note: ${ }^{\mathrm{R}}$ indicates reference category.

A number of socioeconomic variables were also associated with infant mortality, such as mother's education, work status, and exposure to media and household wealth and the religion of the household head. Among community-level variables, the proportion of women using modern contraception and of children receiving the recommended childhood vaccinations was significantly and negatively associated with infant mortality.

Table 3 presents the detailed decomposition of the rural-urban gap in infant mortality by the exposure variables. For simplicity, we have multiplied the coefficients by 1000 . While the positive contribution $\left(2^{\text {nd }}, 3^{\text {rd }}\right.$ and $4^{\text {th }}$ columns $)$ of a covariate indicates that particular covariate contributed to widening the rural-urban gap in infant mortality, the negative contribution of a covariate (e.g., breastfeeding) indicates diminishing the gap. Findings suggest that about 87-99 per cent of the difference in rural-urban infant mortality was explained by the differences in distribution of exposure variables. Although the magnitude of contribution of exposure variables 
differed over the three NFHS surveys, the direction of contribution remained the same for most variables.

Table 3: Decomposition of rural-urban gap in infant mortality risk, National Family Health Survey 1992-93, 1998-99, and 2005-06

\begin{tabular}{|c|c|c|c|}
\hline Covariates & $\begin{array}{l}\text { NFHS-1 } \\
\text { Contribution }\end{array}$ & $\begin{array}{l}\text { NFHS-2 } \\
\text { Contribution }\end{array}$ & $\begin{array}{c}\text { NFHS-3 } \\
\text { Contribution }\end{array}$ \\
\hline \multicolumn{4}{|l|}{ Socioeconomic variable } \\
\hline Wealth & $12.55^{\star \star \star}$ & $13.17^{\star *}$ & $13.29^{* \star *}$ \\
\hline Maternal education & $4.30^{* \star}$ & $6.06^{* * *}$ & $5.50^{* * *}$ \\
\hline Mother work status & -0.35 & 0.69 & 0.03 \\
\hline Mothers' mass media exposure & -0.05 & -1.35 & -1.98 \\
\hline Religion & $0.48^{* *}$ & 0.44 & 0.15 \\
\hline Caste & $-1.15^{\star \star}$ & -0.39 & 0.05 \\
\hline \multicolumn{4}{|l|}{ Demographic Variables } \\
\hline Sex of the child & -0.04 & -0.29 & -0.03 \\
\hline Birth order \& birth interval & 0.05 & -0.14 & -0.38 \\
\hline Maternal age at birth & -0.09 & -0.07 & -0.01 \\
\hline Size of the baby & $0.94^{* \star *}$ & 0.45 & 0.14 \\
\hline Birth order with order 4 or more in the community (\%) & 0.15 & 0.45 & $1.22^{* * *}$ \\
\hline \multicolumn{4}{|l|}{$\begin{array}{l}\text { Maternal and Child Health care-related individual level } \\
\text { variables }\end{array}$} \\
\hline Breastfeeding & $-11.70^{\star \star *}$ & $-10.17^{\star \star *}$ & $-7.61^{* * *}$ \\
\hline Place of delivery & $7.22^{* * *}$ & $4.47^{* \star *}$ & -0.53 \\
\hline \multicolumn{4}{|c|}{ Maternal and Child Health care-related community level variables } \\
\hline Women who know of Oral Rehydration Solution (\%) & -0.21 & $1.13^{* *}$ & $-2.84^{*}$ \\
\hline Cesarean section births (\%) & 0.08 & 0.05 & $3.68^{* *}$ \\
\hline Women using modern contraceptive (\%) & 2.98 & $3.54^{\star *}$ & -0.28 \\
\hline Fully vaccinated children (\%) & $10.63^{\star \star *}$ & 0.69 & $1.98^{\star *}$ \\
\hline \multicolumn{4}{|l|}{ Others } \\
\hline Region & -0.35 & 0.29 & 0.15 \\
\hline Total gap & 25.44 & 19.47 & 14.33 \\
\hline Explained gap & $24.98(98 \%)$ & $18.99(97 \%)$ & $12.49(87 \%)$ \\
\hline Number of observations & 24159 & 21801 & 20399 \\
\hline
\end{tabular}

Note: $\left.{ }^{* \star *} p<0.01,{ }^{\star *} p<0.05 \&{ }^{*} p<0.102\right)$ Coefficients are multiplied by 1000. 
Surprisingly, mother's age at birth, birth order and birth interval played a negligible role in widening or reducing the rural-urban gap in infant mortality risks (Figure 3). The contribution of the proportion of fully vaccinated children and place of delivery diminished from NFHS-1 to NFHS-3. For example, the percentage of children fully vaccinated contributed only 14 per cent to the rural-urban gap in infant mortality risk in NFHS-3 whereas it was about 42 per cent in NFHS-1. The knowledge of ORS has reduced the rural-urban gap in IMR during NFHS-3.

Figure 3: Percentage contribution of each covariate to the rural-urban gap in infant mortality risk in India, National Family Health Survey 199293 and 2005-06

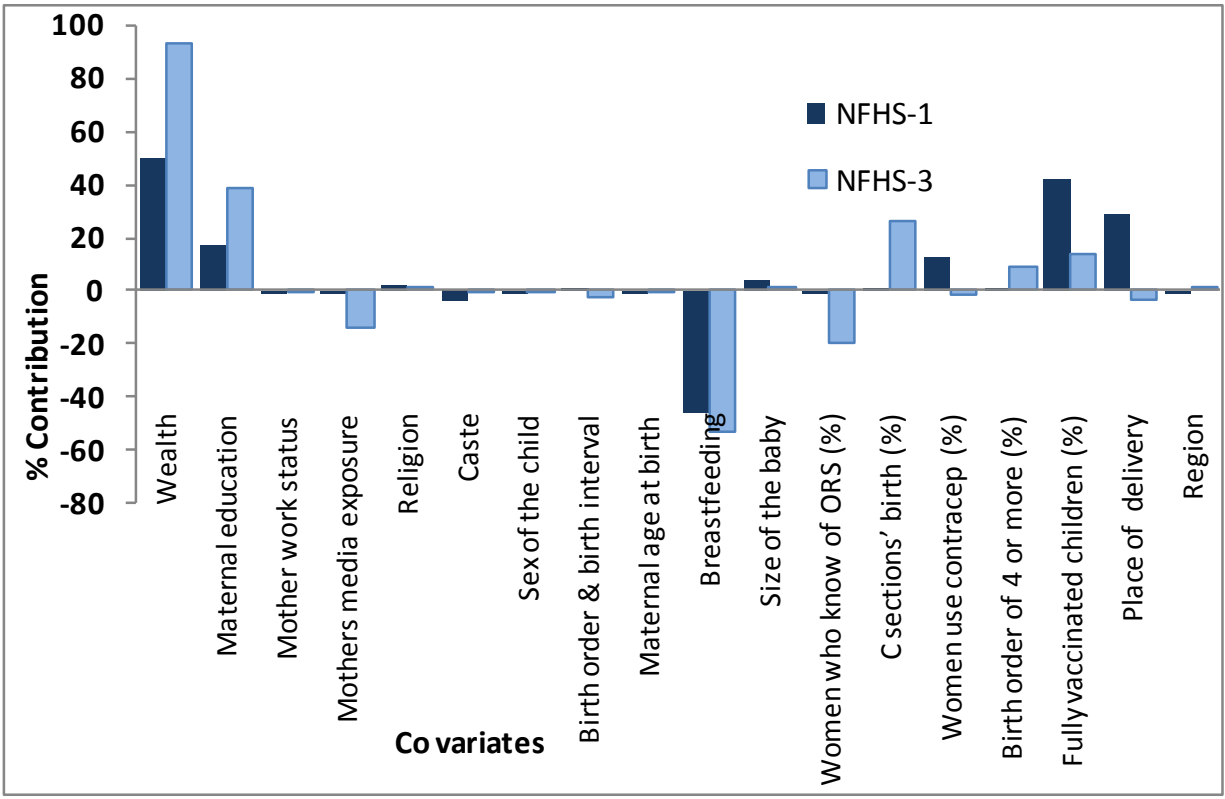

Note: The following are community or PSU level variables: Women who know of ORS (\%); C-section births (\%); Women using modern contraceptive methods (\%); Births of order 4 or more (\%); Fully vaccinated children (\%). 
The contribution of breastfeeding in reducing the rural-urban gap in infant mortality risk was overwhelming. Moreover, breastfeeding has played an increasingly important role in reducing the rural-urban gap in the past two decades. Breastfeeding of rural infants reduced the rural-urban gap in infant mortality by 46 per cent in NFHS-1 and 53 per cent in NFHS-3. On the contrary, household wealth index and mother's education have widened the rural-urban gap in infant mortality. The contribution of household wealth index and mother's education has consistently increased over the three survey rounds. For example, the contribution of household wealth index increased from 49 per cent in NFHS-1 to 93 per cent in NFHS-3. Similarly, the contribution of maternal education increased from 17 per cent in NFHS-1 to 38 per cent in NFHS-3. The percentage of caesarean births in the community was found to widen the ruralurban gap systematically only in NFHS-3. The use of modern contraception methods, baby size, and mother's working status also contributed to the rural-urban gap.

Decomposition results clearly point out the changing dynamics of factors affecting the rural-urban gap in infant mortality. While media exposure, breastfeeding, knowledge of ORS, place of delivery etc. helped in reducing the rural-urban gap in infant mortality, the distribution of wealth and maternal education contributed to widening the gap.

Table 4 presents the trends in socioeconomic, demographic, and community-level factors during 1992-93 to 2005-06. The percentages of children fully vaccinated, institutional deliveries (the percentage of deliveries taking place in health facilities), and of women knowing about the ORS have registered higher improvements in rural areas compared to urban areas during the past two decades. Unlike community-level variables, household wealth disproportionately accumulated among urban areas during this period. The percentage of households in the poorest quintile has increased in rural areas over the past 20 years but has declined in urban areas. The same trend has been observed for maternal education-most non-literate women resided in rural areas, whereas urban areas were marked by relatively higher levels of maternal education. 
Table 4: Trend of the factors affecting rural-urban gap in infant mortality risk over the past two decades by type of residence, India

\begin{tabular}{|c|c|c|c|c|c|c|}
\hline \multirow[b]{2}{*}{ Factors } & \multicolumn{3}{|c|}{ Rural } & \multicolumn{3}{|c|}{ Urban } \\
\hline & NFHS 1 & NFHS 2 & NFHS 3 & NFHS 1 & NFHS 2 & NFHS 3 \\
\hline $\begin{array}{l}\text { Fully vaccinated children }(\%)^{\star} \\
\text { Institutional deliveries in } 3 \text { years preceding }\end{array}$ & 30.9 & 36.6 & 38.6 & 50.7 & 60.5 & 57.6 \\
\hline the survey $(\%)^{*}$ & 16.7 & 24.7 & 36.1 & 58.4 & 65.1 & 69.4 \\
\hline Children breastfed for 6 months or more (\%) & 88.7 & 90.4 & 89.5 & 85.7 & 86.7 & 86.6 \\
\hline Women who know of Oral Rehydration Solution (\%) & 43.2 & 61.4 & 72.5 & 62.0 & 79.4 & 88.1 \\
\hline \multicolumn{7}{|l|}{ Wealth } \\
\hline Lowest & 24.8 & 26.0 & 29.1 & 5.6 & 2.7 & 4.1 \\
\hline Second & 25.0 & 24.9 & 29.0 & 7.3 & 6.2 & 7.4 \\
\hline Middle & 23.0 & 23.5 & 22.1 & 11.8 & 9.9 & 15.6 \\
\hline Fourth & 18.7 & 17.2 & 11.5 & 23.3 & 27.8 & 33.6 \\
\hline Highest & 8.5 & 8.3 & 8.4 & 52.0 & 53.5 & 39.3 \\
\hline \multicolumn{7}{|l|}{ Maternal education } \\
\hline No education & 67.1 & 58.9 & 49.0 & 37.6 & 28.8 & 24.7 \\
\hline Primary education & 16.0 & 16.5 & 15.8 & 16.6 & 15.2 & 11.6 \\
\hline Secondary education & 16.0 & 20.5 & 32.4 & 35.0 & 34.7 & 47.9 \\
\hline Higher education & 0.9 & 4.1 & 2.9 & 10.8 & 21.3 & 15.8 \\
\hline Women using modern contraceptives $(\%)^{\star}$ & 33.3 & 39.9 & 45.3 & 45.3 & 51.2 & 55.8 \\
\hline Caesarean births $(\%)^{*}$ & 1.6 & 4.9 & 5.6 & 5.7 & 14.7 & 16.8 \\
\hline Women regularly exposed to mass media $(\%)^{\star}$ & 47.2 & 49.9 & 54.6 & 80.9 & 87.1 & 87.4 \\
\hline
\end{tabular}

Note: *Borrowed from the respective reports of three NFHS surveys. All figures are expressed as percentages.

\section{Discussion and conclusions}

Infant mortality is widely used as an indicator of the socioeconomic wellbeing of a society. It is an outcome rather than a cause, and hence it directly measures the results of distribution and use of resources. Considerably higher infant mortality in rural India indicates an unequal distribution and use of resources by type of residence. To our knowledge, this study is the first study in India that has systematically investigated the factors that underlie and explain the rural-urban gap in infant mortality. In addition, our study has also documented the changing dynamics of the contribution of communitylevel and socioeconomic factors (from NFHS 1992-93 to NFHS 2005-06) and thus has identified important variables that can significantly contribute to further reducing the rural-urban gap in infant mortality India. 
Our study demonstrated that considerable rural-urban infant mortality differentials persist at both the national and state levels. Substantial mortality disadvantages in rural areas were found in both socioeconomically advanced states (Goa, Kerala) and disadvantaged states (Madhya Pradesh, Assam, and Orissa). The rural-urban gap in infant mortality has remained at the same high level over the last four decades.

The findings suggest that the observed infant mortality differential by type of residence in India is mainly a reflection of the wide rural-urban disparity in socioeconomic and community-level factors. The reduction in the rural-urban gap in infant mortality from the first round of NFHS in 1992-93 to the third round in 2005-06 is due mainly to the improved distribution of community-level factors in rural India. Such community level factors include the share of fully vaccinated children, the share of institutional deliveries (the percentage of deliveries taking place in health facilities), and the share of women who know about the ORS.

Interestingly, the unequal distribution of maternal education and wealth status has tended to widen the rural-urban gap in infant mortality. The unequal distribution of wealth by rural-urban residence has also been confirmed by the findings of the $66^{\text {th }}$ round of National Sample Survey (NSS 2009-2010) (National Sample Survey Office 2011). According to recent NSS statistics, per capita expenditures in urban areas were about $88 \%$ higher than in rural areas on average (National Sample Survey Office 2011). Other studies have also shown that the rural-urban gap in income or consumption either did not narrow or increase marginally after the 1980s (Jha 2000; Fan, Chan-Kang, and Mukherjee 2005; Cali 2007). This may be the result of policies related to industry, food, health, and education, which usually show an urban bias (Fan, Chan-Kang, and Mukherjee 2005). India's first three five-year plans (1951-66) emphasized self-reliance and gave priority to rapid industrialization. This development strategy required a substantial amount of investment in urban industry at the expense of the agricultural sector (Teitelbaum 2004). Similarly, the urban sector benefitted most from India's food security system, known as the Public Distribution System (PDS). Several earlier studies showed that the PDS was biased in favour of the urban sector and found that the quantities of food grains purchased through the PDS were higher in urban areas than in rural areas (Pinstrup-Andersen 1988; Tyagi 1990; Suryanarayana 1995; Gulati, Sharma, and Kahkonen 1996).

In the health sector as well, a greater share of resources is directed towards urbanbased health care services (Balarajan, Selvaraj, and Subramanian 2011). While the rural health facilities cater to about $65 \%$ of the Indian population, only $20 \%$ of health subsidies are directed towards the rural health sector (Bhan 2001). Political intervention and economic forces, as well as governmental policies, have been identified as the sources of the skewed distribution of health care services in favor of the urban sector (Bhan 2001; Kumar 2004). A similar disparity exists between urban and rural areas in 
terms of literacy. Typically, urban populations have better access to schools and also enjoy better quality education (Fan, Chan-Kang, and Mukherjee 2005).

Findings also suggests $\mathrm{MCH}$ care-related programme factors played an important role in reducing rural urban gap in IMR in last two decades. The inclusion of these factors is significant in the context of government policy and programmes. India's programme and policies to improve MCH services was initiated in the early 1900s (Singh 1997). Since then, different committees have recommended different programmes to improve these services (Singh 1997) and, accordingly, different programmes viz. Universal Health Immunisation Programme 1985, Child Survival \& Safe Motherhood 1992 etc. have been adopted to improve MCH services. During our study period, a milestone in $\mathrm{MCH}$ services in India was the inauguration of the Reproductive and Child Health (RCH) Programme in 1997 as a result of India's participation in the International Conference on Population and Development in Cairo. The RCH programme adopted several strategies to reduce infant mortality (MOHFW 2010). Exclusive breastfeeding up to the age of six months was promoted extensively under the RCH programme. Finally, the National Rural Health Mission (NRHM) was launched in 2005 to provide effective health care to the rural population throughout the country with a special focus on 18 states of India. The Janani Suraksha Yojana (JSY), a conditional cash transfer scheme, was initiated under the NRHM to encourage women to give birth in a health facility and had the prime objective of reducing maternal and neonatal deaths. The expansion of JSY has led to substantial increases in the coverage of antenatal and intra partum care, and has probably contributed to the reduction in the numbers of perinatal and neonatal deaths (Lim et al. 2010).

Decomposition analysis by different rounds of NFHS shows that during NFHS-1, community-level factors such as the share of fully vaccinated children and the percentage of institutional deliveries (in a health facility) in the community were equally important, along with socioeconomic factors such as wealth index and maternal education.

Our most striking finding is the role of breastfeeding in reducing the rural-urban gap in infant mortality in India. The rural-urban gap would have been much larger if breastfeeding were not as prevalent in rural India. The analysis of changes of different breastfeeding indicators supports this finding. It has been found that although the share of ever-breastfed children remained almost at the same level over time (95.4\% in NFHS 1 and 95.7 in NFHS 3), the pattern of breastfeeding has been changing over time. For example, the proportion of children who were initiated to breastfeeding within one hour after the birth increased substantially from 9.5\% in NFHS 1 to 24.5\% in NFHS 3 (IIPS 1995; IIPS and ORC Macro 2007). Similarly, the median duration of any breastfeeding (either exclusive or predominant) remained the same in the NFHS 1 and 3 (approximately 24 months). However, the median duration of exclusive breastfeeding 
increased from 1.4 months in the NFHS 1 to 3.7 months in the NFHS 3. A similar pattern has been observed in the case of the median duration of predominant breastfeeding. Previous studies found that delayed breastfeeding initiation increases the risk of neonatal mortality (Edmond et al. 2006; Garcia et al. 2011). It was also found that breastfeeding prevents infant deaths, particularly due to diarrhoeal diseases (Yoon et al. 1996; Betrán et al. 2001). Given that diarrhoea is one of the major causes of death among neonates in India (The Million Death Study Collaborators 2010), breastfeeding has an imperative role to play in reducing infant mortality in rural India.

The examination of the trends of factors contributing significantly to the ruralurban gap in infant mortality also supports the findings of our study. There was a substantial increase in the percentage of households in the middle wealth quintile onwards in urban India. On the other hand, the percentage of people with the lowest and second lowest wealth quintile increased in rural India. That the percentage of population below the poverty line in rural India has been consistently higher than in urban India for the past several decades (Central Statistical Organisation 2008) supports the findings of our study. Similarly, an examination of the rural-urban gap in female literacy in censuses during 1951-1991 also suggests a persisting parallel gap in female literacy by type of residence throughout the period.

The main advantage of this study concerns the simultaneous usage of two rich and reliable data sources (NFHS and SRS). A systematic evaluation of these two data sources revealed that the SRS provides reliable data on child mortality that represents the entire population of India (IIPS 1995; IIPS and ORC Macro 2000, 2007; Bhat 2001; Bhat 2002; Saikia et al. 2011). The major limitation of this study is that it lacks information on community-level determinants such as the availability of health facilities and transportation, which are known as important determinants of child mortality. Unfortunately, neither data source used in our study provides this information. Future studies should explore how to include these variables (possibly by using some alternative data sources) and use more advanced multilevel modelling methods allowing to account for unobserved heterogeneity between different contexts or clusters.

Our findings have important policy implications. First, the persistence of considerable rural-urban infant mortality differentials at both the national and state levels suggest the failure of social and health policies to ensure sustainable health progress for all population groups. The results suggest that in addition to strengthening $\mathrm{MCH}$ programmes in rural areas, substantial efforts must also be made to improve household wealth and female education (including literacy). It should be noted, however, that despite an overall health advantage, enormous differences exists between urban poor women and better off women in accessing to $\mathrm{MCH}$ services (Montgomery 2009). The urban population of India (especially those living in urban slums) also suffer notably from poverty, deprivation, and excess infant and child mortality (Gupta and 
Saikia et al.: Explaining the rural-urban gap in infant mortality in India

Baghel 1999; Vaid et al 2007). Therefore, policy actions directed towards the improvement of the health of the rural population should not be performed at the expense of other disadvantaged groups. 


\section{References}

Akbar, Z.S. (1985). The urban bias in health facilities in Pakistan. Social Science and Medicine 20(5): 473-482. doi:10.1016/0277-9536(85)90362-4.

Arnold, F., Choe, M.K., and Roy, T.K. (1998). Son preference, the family-building process and child mortality in India. Population Studies 52(3): 301-315. doi:10.1080/0032472031000150486.

Balarajan, Y., Selvaraj, S., and Subramanian, S.V. (2011). Health care and equity in India. Lancet 377(9764): 505-515. doi:10.1016/S0140-6736(10)61894-6.

Betrán, A.P., Onís, M. D., Lauer, J.A., and Villar, J. (2001). Ecological study of effect of breast feeding on infant mortality in Latin America. BMJ 323: 1-5. doi:10.1136/bmj.323.7308.303.

Bhagat, R.B. (2011). Emerging pattern of urbanization in India. Economic and Political Weekly XLVI(34): 10-12.

Bhan, G. (2001). India gender profile. Report 62. Sussex, U.K.: Institute of Development Studies.

Bhat, P.N.M. (2001). Recent trend in fertility and mortality in India: A critical reappraisal of data from Sample Registration system and National Family Health Surveys. In: Srinivasan, K. and Vlassoff, M. (eds.). Population-Development Nexus in India: Challenges to the New Millennium. New Delhi: Tata McGrawHill: $72-87$.

Bhat, P.N.M. (2002). Completeness of India's Sample Registration System: An assessment using the General Growth-Balance method. Population Studies 56(2): 119-134. doi:10.1080/00324720215930.

Blinder, A.S. (1973). Wage discrimination: Reduced form and structural covariates. Journal of Human Resources 8(4): 436-455. doi:10.2307/144855.

Bocquier, P., Madise, N.J., and Zulu, E.M. (2011). Is there an urban advantage in child survival in Sub-Saharan Africa? Evidence from 18 countries in the 1990s. Demography 47(2): 531-558. doi:10.1007/s13524-011-0019-2.

Bongaarts, J. (1987). Does family planning reduce infant mortality rates? Population and Development Review 13(2): 323-334. doi:10.2307/1973197.

Cai, L. and Chongsuvivatwong, V. (2006). Rural-urban differentials of premature mortality burden south-west China. International Journal for Equity in Health 5: 13. doi:10.1186/1475-9276-5-13. 
Cain, L. and Hong, S. (2009). Survival in 19th century cities: The larger the city, the smaller your chances. Explorations in Economic History 46(4): 450-463. doi:10.1016/j.eeh.2009.05.001.

Caldwell, J. (1979). Education as a factor in mortality decline an examination of Nigerian data. Population Studies 33(3): 395-413. doi:10.2307/2173888.

Caldwell, J. and McDonald, P. (1982). Influence of maternal education on infant and child mortality: Levels and causes. Health Policy and Education 2(3-4): 251-267. doi:10.1016/0165-2281(82)90012-1.

Cali, M. (2007). Urbanization, inequality and economic growth: Evidence from Indian states. (World development report.) http://siteresources.worldbank.org/ INTWDR2009/Resources/4231006-1204741572978/Cali.pdf.

Central Statistical Organisation (2008). Statistical Abstract India 2007. New Delhi: Government of India 2007.

Chen, A. and Rogan, W.J. (2004). Breastfeeding and the risk of postneonatal death in the United States. Pediatrics 113(5): e435-e439. doi:10.1542/peds.113.5.e435.

Claeson, M., Eduard, R.B., Mawji, T., and Pathmanathan, I. (2000). Reducing child mortality in India in the new millennium. Bulletin of the World Health Organization 78(10): 1192-1199.

Crenshaw, E. and Ameen, A. (1993). Dimensions of social inequality in the Third World: A cross-national analysis of income inequality and mortality decline. Population Research and Policy Review 12(3): 297-313. doi:10.1007/ BF01074390.

Das Gupta, M. (1997). Socio-economic status and clustering of child deaths in rural Punjab. Population Studies 51(2): 191-202. doi:10.1080/003247203100 0149906.

Edmond, K.M., Zandoh, C., Quigley, A., Amenga-Etego, S., Owusu-Agyei, S., and Kirkwood, B.R. (2006). Delayed breastfeeding initiation increases risk of neonatal mortality. Pediatrics 117(3): e380 -e386. doi:10.1542/peds.2005-1496.

Fairlie, R.W. (2005). An extension of the Blinder-Oaxaca decomposition technique to Logit and Probit models. Journal of Economic and Social Measurement 30: 305-316.

Fan, S., Chan-Kang, C., and Mukherjee, A. (2005). Rural and urban dynamics and poverty: Evidence from China and India. International Food policy Research Institute (FCND Discussion Paper 196 \& DSG Discussion Paper 23). 
Forste, R. (1994). The effects of breastfeeding and child mortality in Bolivia. Population Studies 48(3): 211-229. doi:10.1080/0032472031000147996.

Garcia, C.R., Mullany, L.C., Rahmathullah, L., Katz, J., Thulasiraj, R.D., Sheeladevi, S., Coles, C., and Tielsch, J.M. (2011). Breast-feeding initiation time and neonatal mortality risk among newborns in South India. Journal of Perinatology 31(6): 397-403. doi:10.1038/jp.2010.138.

Ghosh, S. and James, K.S. (2010). Levels and trends in Caesarean births: Cause for concern? Economic \& Political Weekly xlv(5): 19-22.

Gould, W.T.S. (1998). African mortality and the new "urban penalty". Health \& Place 4(2): 171-181. doi:10.1016/S1353-8292(98)00009-4.

Gubhaju, B.B. (1985). Effects of birth order and maternal age on infant and child mortality in rural Nepal. Biology and Society 2(1): 15-22.

Gulati, A., Sharma, P., and Kahkonen, S. (1996). The food corporation of India: Successes and failures in Indian foodgrain marketing. College Park, Md., U.S.A.: Center for Institutional Reform and the Informal Sector, University of Maryland (IRIS-India Working Paper 18).

Gupta, H.S. and Baghel, A. (1999). Infant mortality in the Indian slums: Case studies of Calcutta metropolis and Raipur city. International Journal of Population Geography 5(5): 353-366. doi:10.1002/(SICI)1099-1220(199909/10)5:5< 353::AID-IJPG156>3.3.CO;2-G.

Haines, M.R. (1995). Socio-economic differentials in infant and child mortality during mortality decline: England and Wales, 1890-1991. Population Studies 49(2): 297-315. doi:10.1080/0032472031000148526.

Heaton, T.B. and Forste, R. (2003). Rural-urban differences in child growth and survival in Bolivia. Rural Sociology 68(3): 410-433. doi:10.1111/j.15490831.2003.tb00144.x.

Hosseinpoor, A.R., Van Doorslaer, E., Speybroeck, N., Naghavi, M., Mohammad, K., Majdzadeh, R., Delavar, B., Jamshidi, H., and Vega, J. (2006). Decomposing socioeconomic inequality in infant mortality in Iran. International Journal of Epidemiology 35(5): 1211-1219. doi:10.1093/ije/dyl164.

International Institute for Population Sciences (IIPS) (1995). National Family Health Survey (NFHS - 1), 1992-93: India. Mumbai: IIPS.

International Institute for Population Sciences (IIPS) ORC Macro (2000). National Family Health Survey (NFHS - 2), 1998-99: India. Mumbai: IIPS. 
International Institute for Population Sciences (IIPS) ORC Macro (2007). National Family Health Survey (NFHS - 3), 2005-06: India. Vol. I. Mumbai: IIPS.

Islam, M.M. and Azad, K.M. (2008). Rural-urban migration and child survival in urban Bangladesh: Are the urban migrants and poor disadvantaged? Journal of Biosocial Science 40(1): 83-96. doi:10.1017/S0021932007002271.

Jain, A.K. (1985). Determinants of regional variations in infant mortality in rural India. Population Studies 39(3): 407-424. doi:10.1080/0032472031000141596.

Jha, R. (2000) Growth, inequality and poverty in India: Spatial and temporal characteristics. Economic and Political Weekly 35(1): 921-928.

Kembo, J. and Ginneken, J.K.V. (2009). Determinants of infant and child mortality in Zimbabwe: Results of multivariate hazard analysis. Demographic Research 21(13): 367-384. doi:10.4054/DemRes.2009.21.13.

Knöbel, H.H., Yang, W.S., and Ho, M.S. (1994). Urban-rural and regional differences in infant mortality in Taiwan. Social Science and Medicine 39(6): 815-822. doi:10.1016/0277-9536(94)90043-4.

Kravdal, Ø. (2004). Child mortality in India: The community-level effect of education. Population Studies 58(2): 177-192. doi:10.1080/0032472042000213721.

Kuate-Defo, B. and Diallo, K. (2002). Geography of child mortality clustering within African families. Health \& Place 8(2): 93-117. doi:10.1016/S13538292(01)00038-7.

Kumar, N. (2004). Changing geographic access to and locational efficiency of health services in two Indian districts between 1981 and 1996. Social Science and Medicine 58(10): 2045-2067. doi:10.1016/j.socscimed.2003.08.019.

Lim, S.S., Dandona, L., Hoisington, J.A., James, S.L., Hogan, M.C., and Gakidou, E. (2010). India's Janani Suraksha Yojana, a conditional cash transfer programme to increase births in health facilities: An impact evaluation. Lancet 375(9730): 2009-2023. doi:10.1016/S0140-6736(10)60744-1.

Lipton, M. (1977). Why poor people stay poor: A study of urban bias in world development. London: Temple Smith.

Manda, S. (1999). Birth intervals, breastfeeding and determinants of childhood mortality in Malawi. Social Science \& Medicine 48(3): 301-312. doi:10.1016/ S0277-9536(98)00359-1. 
Mohanty, S.K. (2011). Multidimensional poverty and child survival in India. PLoS One 6(10): e26857. doi:10.1371/journal.pone.0026857.

MOHFW (2010). Child health programme in India. http://mohfw.nic.in/WriteRead Data/1892s/6342515027file14.pdf.

Montgomery, M.R. (2009). Urban poverty and health in developing countries. Population Bulletin 64(2). www.prb.org/pdf09/64.2urbanization.pdf.

Moser, K., Shkolnikov, V.M., and Leon, A.D. (2005). World mortality 1950-2000: Divergence replaces convergence from the 1980s. Bulletin of World Health Organization 83(3): 202-209.

Mosley, W.H. and Chen, L.C. (1984). An analytical framework for the study of child survival in developing countries. Population and Development Review 10: 25-45. doi:10.2307/2807954.

Mounts, K., Ngange, K., and Achidi, E. (2011). Relationship between neonatal and infant mortality and mass media exposure in Sub-Saharan Africa. Paper presented at the APHA $139^{\text {th }}$ Annual Meeting and Exposition, October 29 November 2 2011. https://apha.confex.com/apha/139am/webprogram/Paper 247784.html.

Mulholland, E.K., Smith, L., Carneiro, I., Becher,H., and Lehmann, D. (2008). Equity and child-survival strategies. Bulletin of the World Health Organization 86(5): 399-407. doi:10.2471/BLT.07.044545.

National Sample Survey Office (2011). Key indicators of household expenditure in India 2009-2010. Paper presented at the NSS $66^{\text {th }}$ Round, July 2009-June 2010.

Oaxaca, R. (1973). Male-female wage differentials in urban labor markets. International Economic Review 14(3): 693-709. doi:10.2307/2525981.

Office of the Registrar General and Census Commissioner (India) (2013). Implication of Terms Used in Indian Censuses. New Delhi, India: Registrar General of India.

O’Donnell, O., Doorslaer, E.V., Wagstaff, A., and Lindelow, M. (2008). Analysing Health Equity Using Household Survey Data: A Guide to Techniques and Their Implementation. Washington, DC: World Bank Institute Learning Resource Series, the World Bank. http://www.dcp2.org/file/146/Analyzing\%20Health\% 20Equity\%20Using\%20Household\%20Survey\%20Data.pdf. 
Pandey, A., Choe, M.K., Luther, N.Y., Sahu, D., and Chand, J. (1998). Infant and child mortality in India. Mumbai, Honolulu: International Institute for Population Sciences, East-West Center, National Family Health Survey (Subject Report No. 11).

Pham, T.L., Kooreman, P., Koning, R.H., and Wiersma, D. (2011). Gender patterns in Vietnam's child mortality. Forschungsinstitut zur Zukunft der Arbeit, Institute for the Study of Labor (Discussion Paper No. 5741). http://ftp.iza.org/dp 5741.pdf.

Pinstrup-Andersen, P. (1988). Food subsidies in developing countries: Cost, benefits, and policy options. Baltimore, Md., U.S.A., and London: Johns Hopkins University Press for the International Food Policy Research Institute.

Po, J.Y.T. and Subramanian, S.V. (2011). Mortality burden and socioeconomic status in India. PLoS One 6(2): e16844. doi:10.1371/journal.pone.0016844.

Poel, E.V.D., O’Donnell, O., and Doorslaer, E.V. (2007). Are urban children really healthier? Tinbergen Institute (Discussion Paper TI 2007-035/3).

Poel, E.V.D., O'Donnell, O., and Doorslaer, E.V. (2009). What explains the rural-urban gap in infant mortality: Household or community characteristics? Demography 46(4): 827-850. doi:10.1353/dem.0.0074.

Redclift, M.R. (1984). "Urban bias" and rural poverty: A Latin American perspective. The Journal of Development Studies 20(3): 123-138. doi:10.1080/00220 388408421909 .

Registrar General of India (2009). SRS Bulletin. Volume 44 No 1. Vital Statistics Division. New Delhi: Office of the Registrar General of India. http://censusindia. gov.in/vital_statistics/SRS_Bulletins/SRS-Bulletin-October-2009.pdf.

Registrar General of India (2011a). Rural urban distribution of population (Provisional Population Totals). New Delhi: Ministry of Home Affairs. http://censusindia. gov.in/2011-prov-results/paper2/data_files/india/Rural_Urban_2011.pdf.

Registrar General of India (2011b). SRS Bulletin. Volume 45 No 1. Vital Statistics Division. New Delhi: Office of the Registrar General of India.

Rutstein, S.O. (2000). Factors associated with trends in infant and child mortality in developing countries during the 1990s. Bulletin of the World Health Organization 78: 1256-1270. 
Saikia, N., Jasilionis, D., Ram, F., and Shkolnikov, V.M. (2011). Trends and geographic differentials in mortality under age 60 in India. Population Studies 65(1): 73-89. doi:10.1080/00324728.2010.534642.

Sastry, N. (1996). Community characteristics, individual and household attributes, and child survival in Brazil. Demography 33(2): 211-229. doi:10.2307/2061873.

Sastry, N. (1997). What explains rural-urban differentials in child mortality in Brazil? Social Science and Medicine 44(7): 989-1002. doi:10.1016/S02779536(96)00224-9.

Sastry, N. and Burgard, S. (2011). Changes in diarrheal disease and treatment among Brazilian children from 1986 to 1996. Population Research and Policy Review 30(1): 81-100. doi:10.1007/s11113-010-9179-9.

Sathar, Z.A. (1985). Infant and child mortality in Pakistan - some trends and differentials. Journal of Biosocial Science 17(3): 351-360. doi:10.1017/ S0021932000015820.

Shimouchi, A., Ozasa, K., and Hayashi, K. (1994). Immunization coverage and infant mortality rate in developing countries. Asia-Pacific Journal of Public Health 7(4): 228-232. doi:10.1177/101053959400700406.

Shkolnikov, V.M., Andreev, E.M., and Begun, A.Z. (2003). Gini coefficient as a life table function: Computation from discrete data, decomposition of differences and empirical examples. Demographic Research 8(11): 305-358. doi:10.4054/ DemRes.2003.8.11.

Shkolnikov, V.M., Andreev, E.M., Jdanov, D.A., Jasilionis, D., Kravdal, Ø., Vågerö, D., and Valkonen, T. (2012). Increasing absolute mortality disparities by education in Finland, Norway and Sweden, 1971-2000. Journal of Epidemiology and Community Health 66(4): 372-378. doi:10.1136/jech.2009. 104786.

Singh, A., Pathak, P.K., Chauhan, R.K., and Pan, W. (2011). Infant and child mortality in India in the last two decades: A geospatial analysis. PLoS One 6(11): e26856. doi:10.1371/journal.pone.0026856.

Singh, S. (1997). Maternal and child health services in India - past, present and future. Indian Journal of Maternal and Child Health 8(1): 1-4.

Soest, A.H.O. and Saha, U. (2012). Does family planning reduce infant mortality? Evidence from surveillance data in Matlab, Bangladesh. Center for Economic Research (Discussion Paper Series No. 2012-019). doi:10.2139/ssrn.2009853. 
Subramanian, S.V., Nandy, S., Irving,M., Gordon, D., Lambert, H., and Davey Smith, G. (2006). The mortality divide in India: The differential contributions of gender, caste, and standard of living across the life course. American Journal of Public Health 96(5): 818-825. doi:10.2105/AJPH.2004.060103.

Suryanarayana, M.H. (1995). PDS: Beyond implicit subsidy and urban bias - the Indian experience. Food Policy 20(4): 259-278. doi:10.1016/0306-9192(95)00025-9.

Teitelbaum, E.J. (2004). In the grips of a green giant: How the rural sector defeated organized labor in India. Paper presented at the Political Economy Research Colloquium at Cornell University, Ithaca, N.Y.

The Million Death Study Collaborators (2010). Causes of neonatal and child mortality in India: A nationally representative mortality survey. Lancet 376(9755): 1853-1860. doi:10.1016/S0140-6736(10)61461-4.

Trussell, J. and Hammerslough, C. (1983). A Hazards-Model analysis of the covariates of infant and child mortality in Sri Lanka. Demography 20(1): 1-26. doi: $10.2307 / 2060898$.

Tsui, A.O. and Creanga, A. (2009). Does contraceptive use reduce neonatal and infant mortality? Findings from a multi-country analysis. Paper presented at the 2009 Annual Meeting, Population Association of America, April 30-May 22009. http://paa2009.princeton.edu/papers/91181.

Tyagi, D.S. (1990). Managing India's food economy: Problems and alternatives. New Delhi: Sage Publications.

UNICEF (2010). Progress for children. Achieving the MDGs with Equity. http://www.unicef.org/protection/Progress_for_Children-No.9_EN_081710.pdf.

USAID (2006). Avian influenza: Media orientation training notes. USAID. http://www.globalhealthcommunication.org/tool_docs/86/Avian_Influenza_Med ia_Orientation_Workshop_-_Training_Guide.pdf.

Vaid, A., Mammen, A., Primrose, B., and Kang, G. (2007). Infant mortality in an urban Slum. Indian Journal of Pediatrics 74(5): 449-453. doi:10.1007/s12098-0070075-1.

Van Poppel, F. (1989). Urban-rural versus regional difference in demographic behavior: The Netherlands, 1850-1960. Journal of Urban History 15(4): 363-398. doi:10.1177/009614428901500401. 
Victora, C.G., Bryce, J., Fontaine, O., and Monasch, R. (2000). Reducing deaths from diarrhoea through oral rehydration therapy. Bulletin of the World Health Organization 78(10). doi:10.1590/S0042-96862000001000010.

Victora, C.G., Olinto, M.T.A., Barros, F.C., and Nobre, L.C. (1996). Falling diarrhoea mortality in Northeastern Brazil: did ORT play a role? Health Policy and Planning 11(2): 132-141. doi:10.1093/heapol/11.2.132.

Victora, C.G., Wagstaff, A., Schellenberg, J.M., Gwatkin, D., Claeson, M., and Habicht, J. (2003). Applying an equity lens to child health and mortality: More of the same is not enough. Lancet 362(9379): 233-241. doi:10.1016/S01406736(03)13917-7.

Vyas, S. and Kumaranayake, L. (2006). Constructing socio-economic status indices: How to use principal component analysis. Health Policy and Planning 21(6): 459-468. doi:10.1093/heapol/czl029.

Wang, Y., Miao, L., Dai, L., He, C., Li, X., Li, M., Zhou, G., Zhu, J., and Liang, J. (2010). A study on rural-urban differences in neonatal mortality rate in China, 1996-2006. Journal of Epidemiology and Community Health 64(10): 935-936. doi:10.1136/jech.2009.093138.

Woods, R. (2003). Urban-rural mortality differentials: An unresolved debate. Population and Development Review 29(1): 29-46. doi:10.1111/j.17284457.2003.00029.x.

Yoon, P.W., Black, R.E., Moulton, L.H., and Becker, S. (1996). Effect of not breastfeeding on the risk of diarrheal and respiratory mortality in children under 2 years of age in Metro Cebu, Philippines. American Journal of Epidemiology 143(11): 1142-1148. doi:10.1093/oxfordjournals.aje.a008692. 


\section{Appendix: Steps of Fairlie Decomposition (2005)}

According to Standard Blinder-Oaxaca decomposition, the rural-urban gap in the average value of the dependent variable, Y, (here infant mortality) can be expressed as

$$
\bar{Y}^{R}-\bar{Y}^{U}=\left[\left(\bar{X}^{R}-\bar{X}^{U}\right) \hat{\beta}^{R}\right]+\left[\bar{X}^{U}\left(\hat{\beta}^{R}-\hat{\beta}^{U}\right)\right]
$$

where $\bar{X}^{j}$ is a row vector of average values of the independent covariates and $\hat{\beta}^{j}$ is a vector of coefficient estimates for the type of residence $j$. An extension of this decomposition for a non-linear equation, $Y=(X \widehat{\beta})$, can be written as

$$
\bar{Y}^{R}-\bar{Y}^{U}=\left[\sum_{i=1}^{N^{R}} \frac{F\left(X_{i}^{R} \widehat{\beta}^{R}\right)}{N^{R}}-\sum_{i=1}^{N^{U}} \frac{F\left(X_{i}^{U} \widehat{\beta}^{R}\right.}{N^{U}}\right]+\left[\sum_{i=1}^{N^{U}} \frac{F\left(X_{i}^{U} \widehat{\beta}^{R}\right)}{N^{U}}-\sum_{i=1}^{N^{U}} \frac{F\left(X_{i}^{U} \widehat{\beta}^{U}\right.}{N^{U}}\right]
$$

An equally valid expression for decomposition is

$$
\bar{Y}^{R}-\bar{Y}^{U}=\left[\sum_{i=1}^{N^{R}} \frac{F\left(X_{i}^{R} \widehat{\beta}^{U}\right)}{N^{R}}-\sum_{i=1}^{N^{U}} \frac{F\left(X_{i}^{U} \widehat{\beta}^{U}\right.}{N^{U}}\right]+\left[\sum_{i=1}^{N^{R}} \frac{F\left(X_{i}^{R} \widehat{\beta}^{R}\right)}{N^{R}}-\sum_{i=1}^{N^{R}} \frac{F\left(X_{i}^{R} \widehat{\beta}^{U}\right.}{N^{R}}\right]
$$

Here we define $\bar{Y}^{j}$ as the average probability of the binary outcome of the interest group $j$ and $F$ is the cumulative distribution function from the logistic distribution. Here ' $R$ ' stands for rural, ' $U$ ' stands for urban and ' $N$ ' stands for sample size. The first terms in equation (2) and (3) provide an estimate of the contribution of rural-urban differences in the entire set of independent covariates to the rural-urban gap in infant mortality. To find the total contribution, we need to calculate two sets of predicted probabilities by rural-urban and take the difference between the average values of the two.

Identifying the contribution of group difference in specific covariates to the ruralurban gap, however, is not straightforward (Fairlie 2005). Usually, the sample sizes of the two groups are not the same, therefore one needs to follow these steps:

1) First carry out regression for the combined data (rural and urban together) and calculate the predicted probabilities $\widehat{Y}_{l}$, for each rural and urban observation in the sample.

2) Since rural sample is bigger than urban sample, draw a random subsample of rural equal in size to the full urban Sample $\left(\mathrm{N}_{\mathrm{U}}\right)$.

3) Each observation in the rural sample and full urban sample is then separately ranked by predicted probabilities and matched by their respective rankings. This procedure matches the rural infants who have 
characteristics placing them at the bottom (top) of their distribution with urban infants who have characteristics placing them at the bottom (top) of their distribution. Now assume that $\mathrm{Nu}=\mathrm{Nr}$ and a natural one-to-one matching of urban and rural observations exists. Also assume that there are two independent variables to explain the rural-urban gap in IMR $\left(X_{1} \&\right.$ $\left.X_{2}\right)$.

Now, according to Fairlie (2005), using coefficient estimates from a logit regression for a pooled sample, $\hat{\beta}^{*}$, the independent contribution of $X_{1}$ to the ruralurban gap can be expressed as

$$
\frac{1}{N^{U}} \sum_{i=1}^{U} F\left(\hat{\alpha}^{*}+X_{1 i}^{R} \hat{\beta}_{1}^{*}+X_{2 i}^{R} \hat{\beta}_{2}^{*}\right)-F\left(\hat{\alpha}^{*}+X_{1 i}^{U} \hat{\beta}_{1}^{*}+X_{2 i}^{R} \hat{\beta}_{2}^{*}\right)
$$

Similarly, the contribution of $X_{2}$ can be expressed as:

$$
\frac{1}{N^{U}} \sum_{i=1}^{U} F\left(\hat{\alpha}^{*}+X_{1 i}^{U} \hat{\beta}_{1}^{*}+X_{2 i}^{R} \hat{\beta}_{2}^{*}\right)-F\left(\hat{\alpha}^{*}+X_{1 i}^{U} \hat{\beta}_{1}^{*}+X_{2 i}^{U} \hat{\beta}_{2}^{*}\right)
$$

The contribution of each variable to the gap is thus equal to the change in the average predicted probability from replacing urban distribution with rural distribution while holding the distributions of the other variable constant.

However, the assumption of equal sample size is rarely true in practical situations. Since the rural sample is substantially larger, a large number of random subsamples of rural infants (equal size to total urban sample) are drawn to match each of them to the urban sample and calculate separate decomposition. Finally, the mean value of all these separate decomposition estimates is used as an approximate decomposition for the entire rural sample. 
Saikia et al.: Explaining the rural-urban gap in infant mortality in India

Table A1: Descriptive statistics of the covariates used in decomposition of ruralurban gap in infant mortality risk, NFHS 1992-93, 1998-99 \& 2005-06

\begin{tabular}{|c|c|c|c|c|c|c|c|c|c|}
\hline & \multicolumn{3}{|c|}{ NFHS-1 } & \multicolumn{3}{|c|}{ NFHS-2 } & \multicolumn{3}{|c|}{ NFHS-3 } \\
\hline & All & Rural & Urban & All & Rural & Urban & All & Rural & Urban \\
\hline & \multicolumn{9}{|c|}{ Percentage Distribution of sample of all Categorical Covariates } \\
\hline \multicolumn{10}{|l|}{ Maternal education } \\
\hline No Education & 58.9 & 66.8 & 37.5 & 51 & 58.9 & 28.8 & 39.7 & 49 & 24.7 \\
\hline Primary Education & 16.1 & 15.9 & 16.5 & 16.1 & 16.5 & 15.2 & 14.2 & 15.8 & 11.6 \\
\hline Secondary Education & 21.1 & 16.3 & 34.9 & 24.2 & 20.5 & 34.7 & 38.3 & 32.4 & 47.9 \\
\hline Higher Education & 3.6 & 0.9 & 10.8 & 8.6 & 4.1 & 21.3 & 7.8 & 2.9 & 15.8 \\
\hline \multicolumn{10}{|l|}{ Mother work status } \\
\hline Not Working & 70.5 & 65.6 & 83.6 & 69.4 & 64.7 & 82.7 & 71.4 & 65 & 81.8 \\
\hline Working & 29.5 & 34.3 & 16.3 & 30.6 & 35.3 & 17.3 & 28.4 & 35 & 18.2 \\
\hline \multicolumn{10}{|l|}{ Mothers' mass media exposure } \\
\hline Not Exposed & 50.1 & 59.4 & 24.8 & 43.7 & 53.6 & 15.8 & 37.5 & 50.2 & 17.1 \\
\hline Exposed & 49.9 & 40.5 & 75.2 & 56.3 & 46.4 & 84.2 & 62.4 & 49.8 & 82.9 \\
\hline \multicolumn{10}{|l|}{ Religion } \\
\hline Hindu & 75.7 & 77.3 & 71.5 & 74 & 75.9 & 68.4 & 68.5 & 70.6 & 65.2 \\
\hline Muslim & 13.5 & 12.1 & 17.2 & 14.7 & 13 & 19.5 & 16.9 & 13.9 & 21.8 \\
\hline Christian & 6 & 5.8 & 6.4 & 6.7 & 6.4 & 7.4 & 10.1 & 10.5 & 9.5 \\
\hline Others & 4.8 & 4.8 & 4.9 & 4.6 & 4.6 & 4.7 & 4.4 & 5.1 & 3.6 \\
\hline \multicolumn{10}{|l|}{ Caste } \\
\hline Others & 74.5 & 70.9 & 83.9 & 66 & 62.7 & 75.4 & 66.1 & 61.8 & 73.9 \\
\hline Scheduled Castes & 12.7 & 13.9 & 9.7 & 18.6 & 19.4 & 15.8 & 17.5 & 18.3 & 16.3 \\
\hline Scheduled Tribes & 12.8 & 15.2 & 6.4 & 14.7 & 17 & 8.8 & 16.1 & 19.9 & 9.8 \\
\hline \multicolumn{10}{|l|}{ Birth order \& birth interval } \\
\hline First born & 28.3 & 27.2 & 31.5 & 28.9 & 26.7 & 35.2 & 32.6 & 29.7 & 37.6 \\
\hline Second order birth and birth interval less than 24 months & 6.8 & 6.4 & 7.9 & 6.9 & 6.8 & 7 & 8.2 & 7.6 & 9 \\
\hline Second order birth and birth interval more than equal to & & & & & & & & & \\
\hline 24 months & 17.6 & 17 & 19.2 & 18.9 & 17.7 & 22.3 & 20.2 & 18.5 & 22.8 \\
\hline $\begin{array}{l}\text { Third or more order birth and birth interval less than } 24 \\
\text { months }\end{array}$ & 10.9 & 11 & 10.7 & 10.9 & 11.6 & 9.1 & 10.1 & 11.2 & 8.5 \\
\hline $\begin{array}{l}\text { Third or more order birth and birth interval more than } \\
\text { equal to } 24 \text { months }\end{array}$ & 36.2 & 38.3 & 30.5 & 34.2 & 37 & 26.3 & 28.7 & 33 & 22.1 \\
\hline Maternal age at birth (completed years) & - & & & - & & & - & & \\
\hline 11 to 20 year & 28.7 & 30.5 & 23.6 & 69.7 & 30.5 & 23.4 & 61.3 & 27 & 21.6 \\
\hline 21 to 30 years & 57.8 & 55.7 & 63.5 & 29.5 & 57.2 & 64.8 & 37.2 & 59.3 & 67.1 \\
\hline 31 and above & 13.5 & 13.7 & 12.9 & 0.8 & 12.4 & 11.8 & 1.5 & 13.7 & 11.3 \\
\hline \multicolumn{10}{|l|}{ Size of the baby } \\
\hline Average or more than average & 78.3 & 77.9 & 79.6 & 75 & 74.2 & 77.3 & 78.9 & 77.2 & 81.7 \\
\hline Smaller than average & 21.7 & 22.1 & 20.4 & 25 & 25.8 & 22.7 & 21.1 & 22.8 & 18.3 \\
\hline \multicolumn{10}{|l|}{ Place of delivery } \\
\hline Home Delivery & 71.9 & 81.7 & 45.6 & 65.6 & 76.6 & 34.5 & 53.3 & 67 & 31.4 \\
\hline Institutional Delivery & 28.1 & 18.3 & 54.4 & 34.4 & 23.4 & 65.5 & 46.6 & 33 & 68.6 \\
\hline \multicolumn{10}{|l|}{ Region } \\
\hline South & 15.3 & 14.8 & 16.7 & 13.5 & 12.2 & 17.3 & 14.2 & 12 & 17.9 \\
\hline North & 22.8 & 20.2 & 29.8 & 23.7 & 22.3 & 27.4 & 17.9 & 18.7 & 16.4 \\
\hline Central & 23.8 & 26.7 & 16.2 & 21.7 & 23.9 & 15.5 & 22.4 & 23.6 & 20.3 \\
\hline East & 16.2 & 17.7 & 12.3 & 17.1 & 19.3 & 10.9 & 15.5 & 17.2 & 12.7 \\
\hline West & 10.7 & 9.2 & 14.6 & 10.3 & 7.4 & 18.4 & 11.2 & 8.2 & 16 \\
\hline North-East & 11.2 & 11.4 & 10.4 & 13.7 & 14.8 & 10.5 & 18.9 & 20.3 & 16.7 \\
\hline
\end{tabular}


Table A1: (Continued)

\begin{tabular}{|c|c|c|c|c|c|c|c|c|c|}
\hline & \multicolumn{3}{|c|}{ NFHS-1 } & \multicolumn{3}{|c|}{ NFHS-2 } & \multicolumn{3}{|c|}{ NFHS-3 } \\
\hline & All & Rural & Urban & All & Rural & Urban & All & Rural & Urban \\
\hline & \multicolumn{9}{|c|}{ Mean of all Continuous Covariates } \\
\hline Breastfeeding (in months)(continuous) & 16.43 & 16.8 & 15.29 & 17.15 & 17.58 & 15.92 & 16.78 & 17.34 & 15.88 \\
\hline $\begin{array}{l}\text { Wealth Index (continuous) } \\
\text { proportion of women who have ORS knowledge }\end{array}$ & 18.78 & 13.75 & 32.4 & 29.39 & 22.87 & 47.73 & 34.52 & 26.11 & 48.07 \\
\hline (continuous) & 0.75 & 0.71 & 0.82 & 0.84 & 0.81 & 0.91 & 0.75 & 0.68 & 0.85 \\
\hline $\begin{array}{l}\text { proportion of C sections' birth (Continuous) } \\
\text { proportion of women using modern contraceptive }\end{array}$ & 0.2 & 0.1 & 0.22 & 0.14 & 0.12 & 0.19 & 0.11 & 0.07 & 0.18 \\
\hline (Continuous) & 0.1 & 0.06 & 0.2 & 0.12 & 0.07 & 0.23 & 0.15 & 0.12 & 0.19 \\
\hline proportion of Birth order with order 4 or more & & & & & & & & & \\
\hline (Continuous) & 0.29 & 0.31 & 0.23 & 0.28 & 0.3 & 0.19 & 0.23 & 0.27 & 0.15 \\
\hline proportion fully vaccinated children (Continuous) & 0.5 & 0.43 & 0.66 & 0.58 & 0.51 & 0.77 & 0.64 & 0.57 & 0.73 \\
\hline Total Sample & 24159 & 17624 & 6535 & 21801 & 16087 & 5714 & 20399 & 12590 & 7809 \\
\hline
\end{tabular}


Saikia et al.: Explaining the rural-urban gap in infant mortality in India 